\title{
A Six-Year Effect Evaluation of an Occupational Health Intervention - Considering Contextual Challenges
}

\author{
Per Oystein Saksvik, ${ }^{1,}$, Marit Christensen ${ }^{1}$, Siw Tone Innstrand ${ }^{\mathbf{1}}$, Oystein Indergaard ${ }^{1}$, \\ Helene Alnes Vedlog', Maria Karanika-Murray ${ }^{2}$ \\ ${ }^{1}$ Department of Psychology, Norwegian University of Science and Technology, Trondheim, Norway \\ ${ }^{2}$ Centre for Public and Psychosocial Health, Nottingham Trent University, Nottingham, UK
}

Email address:

peros@ntnu.no (P. O. Saksvik)

${ }^{*}$ Corresponding author

\section{To cite this article:}

Per Oystein Saksvik, Marit Christensen, Siw Tone Innstrand, Oystein Indergaard, Helene Alnes Vedlog, Maria Karanika-Murray. A Six-Year Effect Evaluation of an Occupational Health Intervention - Considering Contextual Challenges. American Journal of Applied Psychology. Vol. 10, No. 3, 2021, pp. 70-81. doi: 10.11648/j.ajap.20211003.13

Received: April 26, 2021; Accepted: May 26, 2021; Published: June 16, 2021

\begin{abstract}
Interventions to improve organizations are common in both practice and research, but relatively little evaluation research has focused on the long-term effects of an intervention. This study opens a unique window into the longevity of an intervention's outcomes and the factors that can help to sustain these. In this paper we report a long-term effect evaluation of a comprehensive intervention that focused on developing employeeship and that took place over six years in a University unit (the Intervention Unit, IU). A former evaluation showed that the intervention had been successful in achieving its outcomes in the first three years until 2015. In 2016, a major organizational merger was conducted. This provided a natural opportunity to evaluate the long-term sustainability of the intervention in terms of its effects on the psychosocial work environment. The present long-term effect evaluation is a multi-method study with contextual data from multiple sources and stakeholders. The final survey was administered one year after the merger. In addition to the survey, organizational records were examined and interviews with stakeholders were carried out to examine the contextual issues affecting the intervention. To evaluate the intervention, we used ARK, which is a systematic and validated tool. ANOVA analyses of the intervention- and control groups showed that the positive results were compromised in the follow-up survey (a further three years later). The contextual evaluation with ANCOVA pointed to main changes connected to the organizational merger and especially for the IU.
\end{abstract}

Keywords: Effect Evaluation, Organizational Health Intervention, Psychosocial Work Environment

\section{Introduction}

Organizational interventions are common in both practice and research, but relatively little evaluation research has focused on the long-time effects of an intervention, for practical reasons. As a result, we know little about the mechanisms underlying long-term sustainable intervention outcomes, especially when external change or other programmes threaten to undermine successful results. Therefore, such evaluation opportunities can offer invaluable learnings.

The first evaluations in our lonf-term study showed that the intervention was successful in both the process and effect evaluations conducted [ $1-3]$. The present study describes a long-term follow-up effect evaluation of the intervention, in light of major contextual changes in the form of an organizational merger that took place after the short-term evaluation had been completed. As such, the present study supplements earlier evaluations of this intervention by examining its effects in the long run, while considering contextual challenges in the Intervention Unit (IU) compared to the rest of the organization. In addition, it also helps us to explore the importance of building sustainability in organizational interventions and the usefulness of a systematic approach to intervention evaluation [4].

Sustaining and improving successful organizational interventions involves the ability to identify the key components of an intervention that have been effective. Therefore, intervention research calls for documentation and 
evaluation of both intervention outcomes and the implementation process $[5,6]$. An outcome or effect evaluation answers the question of whether an intervention worked or not [7] by considering changes in individual and organizational outputs such as stress, well-being, absenteeism, or financial targets [1].

In this intervention under study, the effect evaluation showed that the intervention was successful in improving the psychosocial work environment through reducing conflict among employees and strengthening social community, empowering leadership, and increasing trust in management [2]. When an intervention leads to substantial outcomes, it is important to understand which components contributed to that success: to identify what works, for whom, why, how and under which circumstances [8]. In this intervention, such a process evaluation was undertaken in 2016 [3]. This showed that an engaged line manager is essential for maintaining employee motivation and involvement in the longer term, and that this is done through building empowerment and trust, establishing a work group, and integrating support from internal and external consultants; concluding that the intervention had been successful overall (Authors, [1 - 3]. After the intervention was completed, the IU experienced substantial changes which led to a necessary contextual investigation to document the content of these changes. By acknowledging the role of the intervention process and context for intervention outcomes, we can minimize challenges associated with evaluations that focus solely on outcomes or effects. This is because effect evaluation only considers explanations of variations in given outcomes, rather than the mechanisms that explain how organizational intervention programs work [9].

Furthermore, it has been argued that contextual elements are often neglected in intervention research and that the context in which an intervention takes place is one of the most influential elements for intervention outcomes [10 - 14] and therefore if the context changes so may the outcomes. Context is defined as 'situational opportunities and constraints that affect the occurrence and meaning of organizational behavior as well as functional relationships between variables' [15]. In recent years, interest has increased in viewing organizations as continuous collectives of processes that link different players or actors together [16, 17]. In this view, it is through its relations with others that a certain object or individual have power, and the effect of one of them on the other will occur only if these collectives are organized in a way that allow the actors to have an effect [18]. This is in line with principles of Realist Evaluation, which argues that: 'it is not programs that work; rather, it is the underlying reasons and resources that they offer that generate change' [19]. As such, it becomes relevant to consider the complex context in which interventions take place [20] and more specifically how organizational interventions, such as any planned change activity, must adapt to the routines and operations of the organization [21].

The results of the intervention that we followed for six years and had evaluated as successful in the short-term were challenged as soon as the IU faced a new reality. Specifically, major organizational changes were introduced over a relatively short period, highlighting the need to identify concurrent processes that were seemingly unrelated to the intervention, in order to consider elements that may have had an impact on the intervention outcomes, either directly through their role in the implementation of the intervention activities or indirectly by influencing the behaviors of those involved [22, 17]. A contextual analysis can shed light on these processes. Such data can be obtained from interviews or from meeting notes and organizational records, as in this study.

The aim the present study was therefore to conduct a follow-up effect evaluation of a long term employeeship intervention in the context of a major organizational change.

\subsection{The Intervention}

Before we describe the long-term evaluation, it is important to outline the intervention itself and the short-term evaluation that has taken place. This description is necessarily brief but refer the reader to detailed sources of information. The senior management team (SMT) of the organization initiated the intervention after a regular survey highlighted a less-than-optimal psychosocial work environment, rife with interpersonal conflicts, in one administrative unit that then became the intervention unit. The intervention consisted of two complementary parts that were implemented sequentially: the Employeeship Programme (EP) and the Health, Safety, and Environment Project (HSEP) (for more detail on EP see 1. The EP aimed to increase employees' awareness and skills related to interpersonal relationships. It consisted of three mandatory workshops aimed at: 1) reducing interpersonal conflict through developing a positive focus on employee diversity (which was delivered using the Diversity Icebreaker Test [1]); 2) offering practical training in teamwork, communication, and customer service; and 3) promoting positive aspects of the workplace such as more positive interactions among the employees. The broader intervention evaluation indicated that the participants perceived the EP positively and that it had positive effects on relationships at work [1].

The HSEP, on the other hand, was designed to support the continuous development of a positive and health-promoting psychosocial work environment and as such was based on the job demands-resources model $[23,24]$. The HESP aimed to strengthen the links between the EP and the organization's daily life. This was essential, because employees who perceives intervention activities as relevant and proximal to their daily work are more prone to show participation and engagement [25]. The HSEP action consisted of four workshops: 1) establishing a shared understanding of the intervention's purpose, 2) employee training in the organization's conflict management policy, 3) creating procedures for developing a positive work environment, and 4) training and application of new procedures.

The EP and HSEP were implemented by external 
consultants with help from internal Human Resources in cooperation with the SMT. The consultants' aim was to empower the leaders to take responsibility for the intervention process. As such, their role was to train, guide, and support the leaders. Through this, the consultants contributed with the key principles related to participation: management support and intervention fit (see model developed by Nielsen and Noblet, [26]). The researchers (and authors of this study) were involved in the evaluation of the intervention but not its implementation.

To supplement the intervention process, a Work Group (WG) was established as part of the HESP to facilitate the implementation of the intervention. The WG consisted of the department manager, a union representative, a safety representative, and employee representatives. Its purpose was to be a collective voice for the employees and to provide guidance and support to the management. Through systematic and ongoing work, the WG helped to keep the intervention momentum - for example, through mini evaluations, adjustments, communication of the results, and supporting participation. At the end of the intervention, the unit decided to retain the $\mathrm{WG}$ as it was regarded as useful and important.

\subsection{The Context of the Long-term Evaluation}

After the intervention was completed in 2015, a number of changes occurred in the IU. Specifically, these included a merger and a major reorganization, no available support from the external consultant firm, increased turnover, changes in management, and termination of the work group, and these changes emerged between the end of the intervention in 2014 and the new survey in 2017. These contextual issues had a special impact on the IU compared to the rest of the university especially that they received many new employees (almost a 50\% turnover) and this may have had a negative impact on the parameters used to evaluate the effects of the intervention; specifically interpersonal conflict and social community, as well as the covariates empowering leadership and trust in management. This study was an opportunity to examine intervention effects after major contextual change. We can therefore expect that because of their negative nature, the contextual issues listed above had a special impact on the IU compared to the larger organization where the turnover was close to cero.

It was possible that the positive impact of the intervention on the psychosocial work environment reported between the baseline assessment (2012) and the post-intervention assessment (2014) may have not been maintained the followup (2017) due to these changes in the context. For the longterm evaluation, we thus maintained the same two hypotheses on the content of the intervention as per the first effect evaluation and added one related to the context of the intervention. More specifically we hypothesized that:

Hypothesis 1: Positive changes reported in interpersonal conflict between baseline and post-intervention were not maintained in the follow-up investigation.

Hypothesis 2: Positive changes reported in social community between baseline and post-intervention were not maintained in the follow-up investigation.

Hypothesis 3: Increased levels of interpersonal conflict and decreased social community experienced by those in the IU are linked to changes in empowering leadership and trust in management.

\section{Method}

\subsection{Procedure and Participants}

Early in 2012, the intervention unit (IU) at a large university initiated an intervention which was implemented because an internal survey showed that interpersonal conflicts were widespread and that the psychosocial work environment was in need of improvement. The interpretation of the results from the survey in 2012 was carried out by an external consultancy.

The intervention was launched in February 2012 (just after the internal survey) and completed in March 2014. In addition to the description of the intervention provided earlier, a more detailed description can be found in [1 - 3]. The evaluation was in two parts: effect evaluation, for which a self-report survey was used, and context evaluation for which the contextual variables and organizational records from the University were used.

The survey was undertaken at baseline in 2012 and administered at the whole university at the end of the year, represents the baseline for the effect evaluation. It was administered again post-intervention (October 2014) and at follow-up (2017) across the whole university $(\mathrm{N}=3,855$ at post-intervention and $\mathrm{N}=4998$ at follow-up), including the IU ( $n=59$ at post-intervention and $n=79$ at follow-up). postintervention and $n=79$ at follow-up). All employees in the organization were invited to participate (for demographic information see [1 - 3] and Table 1). Response rates ranged from $53.6 \%$ at baseline for the whole University to $93.7 \%$ for the post-intervention survey at the IU (Table 1).

Table 1. Descriptive statistics for survey respondents.

\begin{tabular}{llll}
\hline Group & Invitations & Respondents & $\begin{array}{l}\text { Response } \\
\text { rate }\end{array}$ \\
\hline baseline University* & 5637 & 3023 & $53.6 \%$ \\
baseline IU & 60 & 43 & $71.7 \%$ \\
post-intervention University* & 5237 & 3855 & $73.6 \%$ \\
post-intervention IU & 63 & 59 & $93.7 \%$ \\
follow-up University* & 7290 & 4998 & $68.5 \%$ \\
follow-up IU & 94 & 79 & $84.0 \%$ \\
\hline
\end{tabular}

Note. *IU not included

\subsection{The Survey}

We used KIWEST, which is a working environment and working climate intervention tool developed by four of Norway's largest universities for use in the academic sector. KIWEST I was used at baseline in 2012 and KIWEST II was used post-intervention in 2014 and at follow-up in 2017, and there are some minor differences (described below) in what 
scales these questionnaires used to measure certain factors.

Table 2. Mean and Standard Deviations for the study variables.

\begin{tabular}{|c|c|c|c|c|c|c|}
\hline Variable & M NTNU & M IU & SD NTNU & SD IU & N NTNU & N IU \\
\hline Interpersonal conflict 2012 & 2.06 & 2.31 & 1.01 & .99 & 2978 & 43 \\
\hline Interpersonal conflict 2014 & 2.26 & 2.03 & .99 & .93 & 3838 & 59 \\
\hline Interpersonal conflict 2017 & 2.27 & 2.47 & .96 & .84 & 4980 & 79 \\
\hline Social community at work 2012 & 3.79 & 3.61 & .78 & .84 & 3002 & 43 \\
\hline Social community at work 2014 & 3.98 & 4.15 & .75 & .70 & 3849 & 59 \\
\hline Social community at work 2017 & 3.96 & 3.86 & .76 & .74 & 4984 & 79 \\
\hline Empowering leadership 2012 & 3.26 & 2.87 & 1.07 & .92 & 2948 & 42 \\
\hline Empowering leadership 2017 & 3.72 & 3.22 & .91 & 1.05 & 4957 & 79 \\
\hline Trust in management 2012 & 3.87 & 3.62 & .73 & .82 & 2972 & 42 \\
\hline Trust in management 2014 & 3.91 & 3.62 & .74 & .80 & 3837 & 59 \\
\hline Trust in management 2017 & 3.90 & 3.66 & .75 & .73 & 4955 & 77 \\
\hline
\end{tabular}

The survey is described in detail in a former publication from the study [2] and included questions covering demographic information, subjective occupational health, and other work-environment and organizational climate scales including the ones used in the present investigation. The following scales were selected to address the research question: Interpersonal conflict, Social community at work, Empowering leadership, and Trust in management.

Internal reliability Cronbach's alpha for all scales are shown in Table 3. All scales had an $\alpha>.7$, which is considered the lowest acceptable [31].

Table 3. Cronbachs alpha for the indexes in the study.

\begin{tabular}{llll}
\hline Variables & baseline & post-intervention & follow-up \\
\hline Interpersonal conflict & 0.91 & 0.86 & 0.85 \\
Social community at work & 0.85 & 0.83 & 0.83 \\
Empowering leadership & 0.87 & 0.90 & 0.89 \\
Trust in management & 0.83 & 0.83 & 0.84 \\
\hline
\end{tabular}

Note. *Cronbachs alphas are based on the University sample

The questionnaire was sent to all university employees by e-mail, using the Select Survey (www.selectsurvey.net) online survey system. Reminders were sent by email about three and six weeks later. If employees answered fewer than half of the questions of any scale within the survey, their responses were excluded from the analyses.

\subsection{Analytical Approach}

For the effect evaluation a two-way $(2 \times 3)$ factorial ANOVA was run to compare the IU with the rest of the university, examining group belonging over three points in time. Two separate ANOVAs are used to examine group differences between baseline and post-intervention, and between post-intervention and follow up (contextual changes). In addition, a two-way independent ANCOVA was conducted to examine the effects of empowering leadership and trust in management on the dependent variables interpersonal conflict and social community at work.

The contextual analysis was based on a review and narrative interpretation of the contextual variables, with secondary data from organizational records, intervention records, notes from meetings, and material from interviews with stakeholders that were carried out as part of the short term evaluation (see $[1,3]$ ). The contextual analysis covers a comprehensive assessment of the contextual factors around the intervention over its course and describes the merger, support from the external consultant firm, turnover, and the working group.

\section{Results}

\subsection{Effect Evaluation}

For interpersonal conflict, the $2 \times 3$ ANOVA showed a significant main effect of time $(F(2,11,971)=4.16, p=.016)$ and a significant interaction effect $(F(2,11,971)=3.95, p=.019$; see Figure 1). Between baseline and post-intervention, an interaction effect indicated that the levels of interpersonal conflict had decreased for the IU over time, but increased for the rest of the university $(F(1,6,901)=5.38, p<.05$, reported in previous study [2]. Between post-intervention and follow-up, the ANOVA indicated a significant interaction, where interpersonal conflict had increased over time for the IU, more so than for the rest of the university $(F(1,8,952)=6.22, p=.013)$.

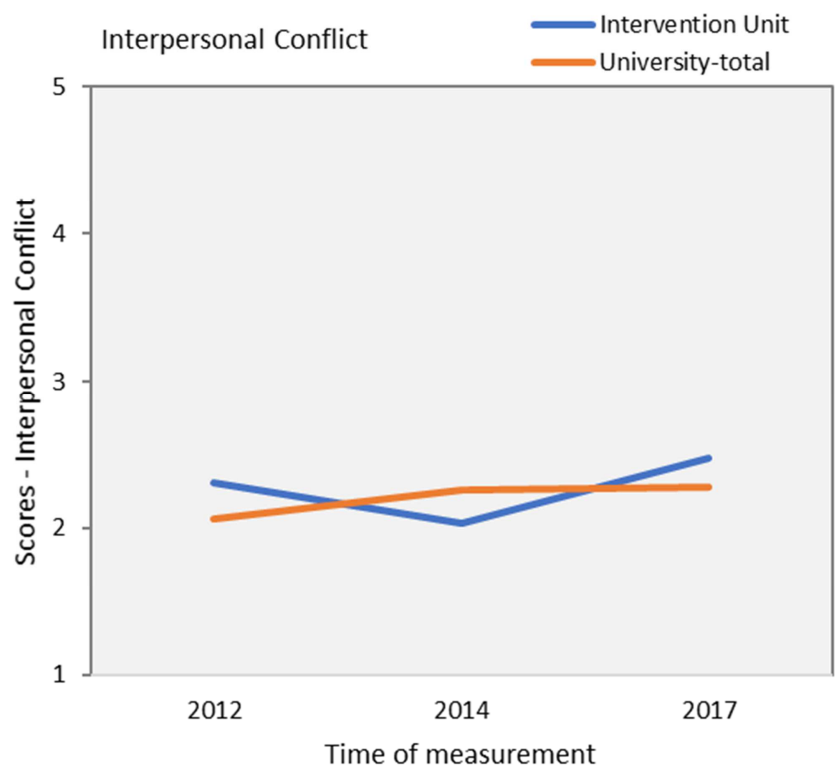

Figure 1. Development over time for Interpersonal Conflict. 
For social community, the $2 \times 3$ ANOVA analysis showed significant main effects of time $(F(2,12,010)=10.85, p$ $<.001)$ as well as a significant interaction $(F(2,12,010)=$ $3.52, p=.03$; see Figure 2). Between baseline and postintervention, an interaction effect showed that social community had increased more over time for the IU than within the rest of the university $(F(1,6,936)=5.13, p<.05$, as reported in [2]. Between post-intervention and follow-up, the ANOVA found that social community had decreased over time for the IU, and not for the rest of the university $(F(1$, $8,967)=4.41, p=.036)$.

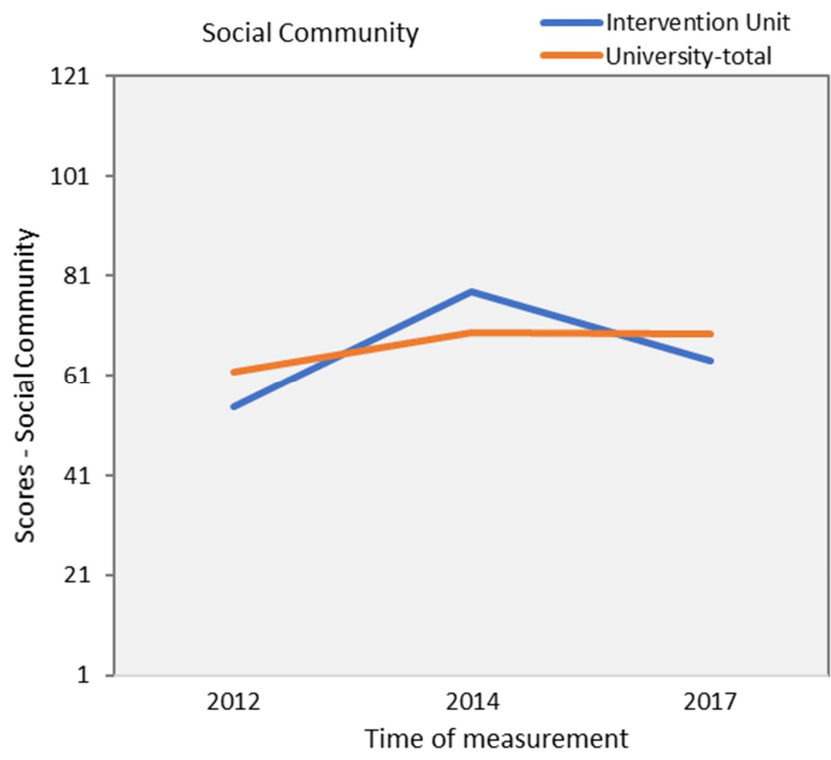

Figure 2. Development over time for Social Community.

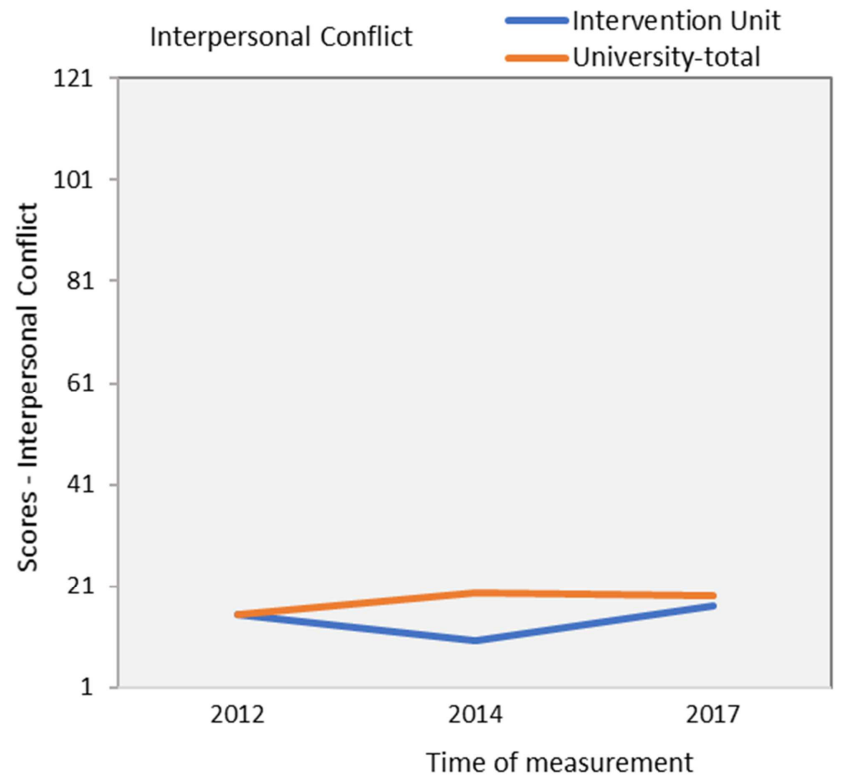

Figure 3. Development over time for Interpersonal Conflict with Leadership and Trust in Management as covariates.

After including empowering leadership and trust in management as covariates in a two-way $2 \times 3$ ANCOVA analysis with interpersonal conflict as the dependent variable, the results showed a significant main effect of group belonging $(F,(1$, $11,641)=5.28, p=.022)$, as well as a significant interaction effect between group belonging and time $(F(2,11,641)=2.96$, $p=.051)$. See Figure 3. Both covariates were significantly related to interpersonal conflict, empowering leadership $(F(1$, $11641)=70.05, p<.001)$ and trust in management $(F(1,11,641)$ $=1589.49, p<.001)$. Covariates included in the model are evaluated at the following values: empowering leadership $(58,36)$ and trust in management $(65,31)$.

There was a significant increase in interpersonal conflict for the IU between post-intervention $(\mathrm{M}=2.03)$ to follow-up $(\mathrm{M}=2.47)(p=.005)$. This change was not found for the rest of the university.

For social community, there was an increase in the IU between baseline $(M=3.62)$ and post-intervention $(M=4.16)$, and the same was found for the rest of the university, from baseline $(\mathrm{M}=3.80)$ to post-intervention $(\mathrm{M}=3.98)$. Both these changes were significant $(p<.001$; as reported in previous study [2]). The IU showed a decrease in social community from post-intervention to follow-up $(\mathrm{M}=3.87)$, and this change was found to be significant $(p=.022)$. This change was not found for the rest of the university.

Empowering leadership increased for the IU between baseline $(\mathrm{M}=2.87)$ and post-intervention $(\mathrm{M}=3.35)$, and this change was significant $(p=.023)$. The same was true for the rest of the university, from baseline $(M=3.26)$ to postintervention $(\mathrm{M}=3.85)$, which also was significant (as reported in previous study [2]). A decrease in empowering leadership was found for the IU between post-intervention and follow-up $(\mathrm{M}=3.22)$. This change was also found for the rest of the university from post-intervention to follow-up $(\mathrm{M}=3.73)$, where only the latter was significant $(p<.001)$.

No significant changes in trust in management were found between post-intervention and follow-up.

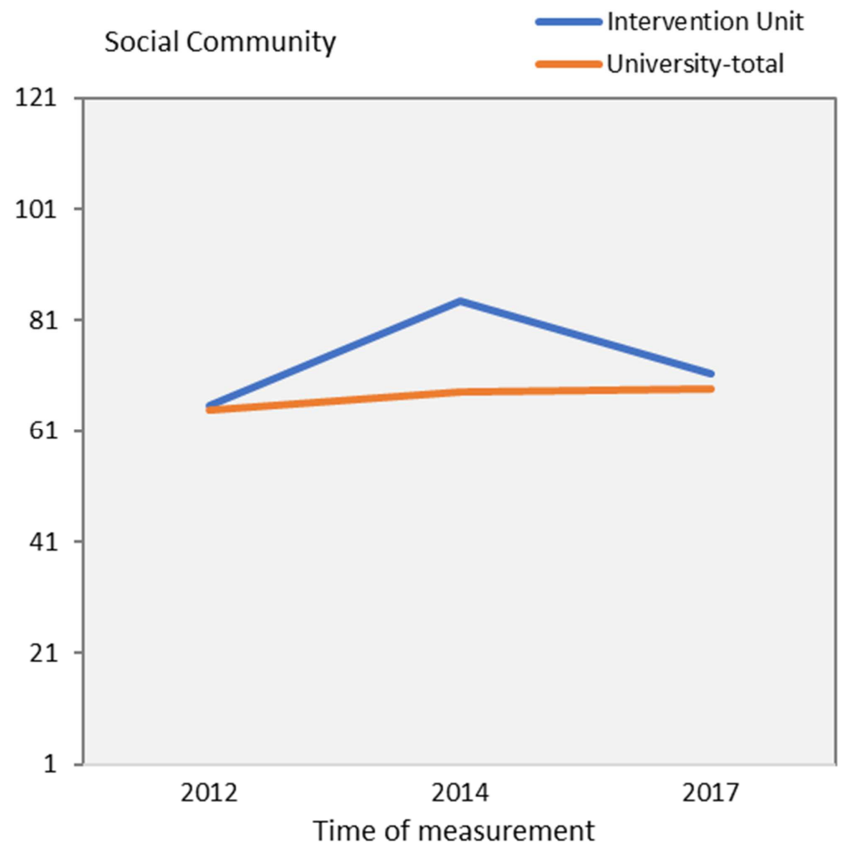

Figure 4. Development over time for Social Community with Leadership and Trust in Management as covariates. 
When including empowering leadership and trust in management as covariates in a two-way $2 \times 3$ ANCOVA cubed analysis with social community as the dependent variable, the results show a significant main effect of group belonging $(F(1,11,661)=10.01, p=.002)$, a significant main effect of time $(F(2,11,661)=8.93, p<0.001)$, and a significant interaction effect $(F(2,11,661)=5.31, p=.005)$. See Figure 4 . Both covariates were significantly related to social community, empowering leadership $(F(1,11661)=$ $607.11, p<.001)$ and trust in management $(F(1,11661)=$ $1899.29, p<.001)$. Covariates included in the model are evaluated at the following values: empowering leadership (36) and trust in management $(65,27)$

Overall, the changes over time in the variables measured indicates that the effect of the intervention between the first two waves (baseline and post-intervention) of the survey was not evident in the next two waves (post-intervention and follow-up), supporting Hypotheses 1 and 2.

\subsection{Contextual Analyses}

We start the contextual analysis with a discussion of the merger, which was the major change and immediate that could have impacted on the sustainability of the intervention and then present additional contextual factors that the examination of organizational and intervention records highlighted. Together, these are factors that emerged as important for affecting the principles and elements of the intervention discussed in the Introduction.

The merger. The merger started early in 2016 and was completed by mid-2017. Process evaluations carried out prior to the merger indicated that only $38 \%$ of employees at the university were positive about the merger [32]. Of relevance to our study, it was further found that the merger would be most demanding for the administrative employees (including the IU department that consist of only administrative employees). This is because a major reorganization like this entails initiatives related to digitalization, standardization, and automation of work tasks and services [33-34]. This restructuring had a substantial impact on the employees including more reports of sleep problems [35, 36, 34]. Several studies also support the fact that stress during merger in the university sector negatively affects employees in the form of reduced health [37, 38]. Based on more pressure on effectiveness and digitalization initiatives during the merger, this has also led to a burden on the employees that resulted in qualitative and quantitative job insecurity [39, 40, 34].

Support from the external consultant firm. The consultant firm had a great impact on the intervention from the start when they were responsible for the Employeeship Program (EP) in 2013 and the Health, Safety, and Environment Project (HSEP) in 2015. In many ways they were the driving force of the intervention process [4]. After the intervention ended in 2015, they had no official tasks in the intervention unit.

Staff turnover. Table 1 shows that the number of employees grew from 63 to 94 in the three years between post-intervention and follow-up in the IU. The new employees came from other academic institutions with their own culture and a few of them were not integrated in the IU but continued to work from other geographical areas in the country. The unit also initiated a change of unit manager in the year before follow-up (during 2016).

The work group. The work group enabled the intervention process to be dynamic and adjusted to the local context [4, 41]. The work group was however terminated when the intervention ended in 2015.

The contextual analyses in sum supported Hypothesis 3.

\section{Discussion}

The results of this study indicate that the positive effects found in the post-intervention survey were compromised in the follow-up survey three years later. Maintaining the positive effects of an intervention over years in the long term can therefore be problematic. This can have important implications for understanding and planning for intervention sustainability.

Based on the contextual analysis, this decrease in gains is understandable since various issues had appeared between post-intervention and follow-up, and specifically a merger that affected the IU more than it affected the rest of the organization. The growth of IU after the merger with 31 new employees (almost a 50\% growth) who had not taken part in the intervention itself may help to explain the loss of intervention gains. It is not possible for an intervention to have long-term sustainable effects if the context of the organization changes substantially over time as in this case. For example, the strategies that employees had learned during the intervention period may not be transferable to new employees without repeating some of the content of the Employeeship program. Similarly, substantial changes in staff may bring fractures in the organizational culture and move it away from the established gains. This does not mean organizational interventions are wasted effort, but that they should be part of a healthy 'lifestyle' of an organization. We can, however, extract learnings from this case about what issues must be considered to secure positive and sustainable intervention effects.

The contextual analysis highlighted several factors of relevance to understanding the intervention effects. First, the intervention unit was involved in an organization-wide merger that was implemented one year after the intervention. The merger particularly affected administrative employees, who were the majority of staff in the Intervention Unit. Their engagement and integration in the IU would not have been the same as for the existing staff. Second, there was an increased staff turnover in the IU as a result of the merger, of both managers and employees at other grades. This may have impacted on morale, workloads/work priorities, and team cohesiveness. Third, the team of external consultants who been responsible for implementing the EP and the HSEP and who was a driving force in the intervention [4] had no role in the IU after the intervention ended. Finally, the Work Group that was established during the intervention to help secure 
participation and adjust the intervention to the local context $[41,4]$ had been dissolved. Substantial resources were lost with the team of consultants and the Work Group. We discuss the importance of these in more detail next.

The merger. Mergers lead to changes in an organization's defined structures [42] and, as a result, they are often disruptive, contested, and costly in both human and financial terms [43]. In the context of change, people are more sensitive to their circumstances, and negative experiences produce stronger and more lasting effects than positive ones [44]. As such, although intervention participants, in this case IU staff, may build stronger resources as a result of the intervention [45], subsequent developments, in this case the merger, may also increase demands, rendering previous resources insufficient in this new context. In addition, [46] concluded that employees are more focused on their immediate work environment than on the meaning and significance of larger organizational-level change. The merger that the whole organization went through had an impact that was of special and immediate significance for the IU. The evaluation of this department by the internal Health and Safety team stated: "There was some turmoil this winter related to restructuring in connection with the merger, with this having resulted in increased sickness absence" [36]

Staff turnover. The contextual analysis pointed to increased managerial turnover in the IU. The importance of the management's role in the success of any work organization intervention has been long acknowledged [47, $48,49,7,14]$ as well as being highlighted an area important for healthy change [50]. One problem often encountered in intervention work is that external experts, such as consultants, often fail to involve stakeholders in the intervention [51]. The immediate manager and their support with the intervention is especially crucial and it is therefore important to employ strategies to achieve ownership by this group [52] secure their commitment, and maintain buy-in in the intervention [53]. In the intervention that we studied, this was achieved through the consultants' efforts to guide, train, and empower the managers in the intervention. However, if such crucial support is tied to specific individuals, and these individuals leave the unit, the situation can become very difficult and continued ownership of the intervention may be challenged [45].

Furthermore, the merger also resulted in increased turnover amongst employees. Considering the employees' role as active participants involved in determining the quality of intervention efforts [54], it is reasonable to assume that an increase in new employees in the IU will influence intervention effects in the long-term. The assumption that the intervention targets all employees is no longer true when the staff composition of the IU changes, either in the form of employees leaving or new employees joining the unit [55]. Because these new employees have not been involved in and may not even be aware of the intervention aims and activities, any positive changes in attitudes, behaviors, or values in the IU may be diluted. Mixing organizational units as a result of a merger may lead to challenges with integrating different sub-cultures. Even as the pre-merger aspects such as the Work Group and intervention management supported a good "fit" between the intervention and the earlier organizational context, the merger brought inevitable changes to the organizational context through employee turnover. Being unprepared for such events could influence planned potential positive effects $[56,57]$

Culture change. Acculturative stress can occur during fusion processes, and cultural differences between the respective institutions often present challenges e.g., [58, 59, 60]. The merger involved higher education institutions that would tend to share fundamental characteristics, goals and values. But as stated by Buono et al. [61], even organizations that appear similar and should have similar cultures may have underlying differences that can undermine their integration. For example, [62] discuss differing values and loyalties between university employees and university college employees. This especially regards governance, where university employees may not be as tolerant of bureaucratic and hierarchal "modes of operation" as university college employees [62]. As such, organizations that may appear similar on the surface may have differing cultures. However, as the main remit of the IU in this study was administrative responsibilities, they may have been less influenced by these cultural classifications than units with academic responsibilities, as these classifications stem largely from academic tradition $[62,63]$. "Sub-systems" such as administrative units can be very individualistic in behaviors and culture, but they are nevertheless subject to disciplinary ties that exist to hold certain groups together [63]. As such, the context of merging organizations pre-merger becomes relevant, as differing principles may shape and characterize how they perceive culture (how they do things) [64].

Furthermore, a merger process can initiate multiple feelings of threatened identity and uncertainty, which can often lead to feelings of anger, grief and resistance to change [65 - 67]. We know that individuals define themselves as members of social categories and groups, and attribute themselves to typical traits typical of these categories as per Social Identity Theory, [68] and Self-categorization Theory, [69]. This perception of the self as a group member provides the basis for perceptual, attitude and behavior-related effects of group membership. In addition, an asymmetric power and size ratio between units to be merged can be seen as extra challenging $[66,67,70]$. Several of these forces describe the IU, with substantial numbers of employees feeling very dissatisfied with the merger and expressing frustration and dissatisfaction [36]. As the context of change makes employee sensitive to their circumstances, heightened awareness of their membership can trigger comparisons with "other" organizations [71]. [7] states how participation in an intervention may cause an intervention group to view themselves as an "in-group" as opposed to other groups not receiving the intervention. Such an identification processes may impact on the integration processes of a merged unit, such as the IU, and cause a division between employees. As 
shown by the findings of [57], employees not part of an intervention steering group reported poorer well-being postintervention, which may have been due to their identification as the "out-group" [7]. Similarly, Giæver and colleagues found unexpected negative effects in terms of differences between participants and non-participants of an intervention [72]. In particular, participants showed more organizational commitment and engagement, and an improvement in psychosocial work environment, compared to nonparticipants [73]. Bearing in mind the detrimental effects that mergers can have on employees, it becomes important to consider both social identification processes and cultural dimensions to address the likelihood of high levels of stress and conflict $[62,74]$

External consultants and the Work Group. The external consultants were, in earlier studies of this intervention, identified as a driving force behind the intervention [4]. As such, their role in the intervention is likely to have influenced its effects. However, as discussed above, the consultants worked to secure participation and ownership of the intervention both through guiding, training, and empowering management, and through the establishment of the Work Group. As such, the departure of the external consultants in the intervention may not have been as detrimental to the intervention's effects, as it can be argued that they contributed to creating capacity in the internal change agents throughout the intervention.

In terms of the role of the internal change agent for employees' reaction to mergers, the Work Group was identified by participants as one of the most important aspects of how interventions should be managed to produce sustainable effects in the long term [4]. In the context of mergers, a bottom-up approach is recommended, where employees are provided opportunities to voice their expectations and concerns, which can help manage misconceptions and unmet expectations [75, 71]. Having a work group or committee with representatives for employees can function in a bottom-up manner to help organizations build on the knowledge of the type and scope of challenges they meet as a result of the merger [76], as well as insure participation of employees in matters that affect their work situation. In addition, it can function as a resource to disseminate top-down information, a strategy which has been shown to have a significant negative relationship with anxiety about the change at the time of merger announcements [77].

It was recommended that the Work Group in the intervention should be integrated into the organizational structure, to give a continuous focus on manager-employee communication, as well as employee participation and engagement [4]. However, our contextual analysis showed that the Work Group was disbanded after the intervention and the benefits of such a resource were dissolved. In addition, this not only led to the withdrawal of possibly beneficial resources, but also had the ability to interfere with the positive effects of the intervention that materialized premerger. [77] showed how one unit, after a reorganization following an intervention, perceived the loss of gains from a "problem-solving committee" established in the intervention, after their unit directors who supported the committees were replaced. As such, managerial turnover may also play a role in involvement and participation of employees.

It is suggested that non-significant or negative results more often are caused by contextual and process factors than by the content of any given programs or activities [78]. Although earlier evaluations of this intervention showed that it has been implemented well and was successful $[1,2,4]$, this evaluation shows that these effects have changed. Using a longitudinal approach allows us to compare participants ratings of their psychosocial work environment both before and after the intervention, as well as before and after the changes identified in the contextual analysis. In addition, through earlier evaluations of both the intervention's implementation process and effects, we have a richer understanding of what caused the observed effects [79], which clarifies how the contextual challenges identified had an impact on the intervention effects.

Healthy change. Organizational change is stressful [80, 81]. The Healthy Change Processes (HCP) framework outlines the necessary conditions that help to maintain or enhance mental health during organizational change [50]. According to the HCP, four dimensions characterize healthy change: awareness of diversity (the importance of being aware of the different reactions employees may have towards the change), manager availability (the importance of managers being present during change and of good information flow and dialogue between manager and employees), constructive conflicts (represents the acceptance of resistance as natural and human response to change and finding ways to appraise employee reactions), and role clarification (the importance of establishing new roles and tasks early on in the change process to avoid role ambiguity and conflict). The factors that the contextual analysis identified fit very well with the HCP framework. Intervention effects could have been sustained in the longer term if these HPC dimensions had been considered earlier in the process. Under the umbrella of the HCP, contextual analysis can be integrated as a standard part of any intervention evaluation to help adjust the activities and support sustainable effects [82].

\section{Methodological considerations}

Any empirical work has limitations as well as strengths. In relation to this long-term evaluation, we outline the following: the experimental or rather quasi-experimental design (e.g., use of baseline measures and participant randomization) and the limitations of self-report measures (e.g., social desirability and self-serving bias).

It was not possible to have a true evaluation baseline since the first survey was administered after the start of the intervention but before its completion. Thus, it is likely that the intervention had already had an impact on the outcomes and the timing of the data collection may have impacted on the findings. However, the data were collected on three occasions and using standardized and validated measures [27] that were appropriate for university settings, which added to 
the strength of the evaluation. Even if pre-post valuation was not possible, it was possible to gauge changes over time at the group level.

In addition, random allocation of participants into an intervention and a control group was not practical in this organization. Randomization is a way to enhance certainty that any changes could be attributed to the intervention rather than to the characteristics of the participants within the group - it is also most challenging in intervention research [82]. It is possible that at baseline the intervention group participants were already experiencing positive changes or that being in the intervention group produced a Hawthorne effect in that group. By using existing groups which were similar in their broad job and environment characteristics, our evaluation utilized a quasi-experimental design, which is an appropriate approach in applied research. Furthermore, including both a control group and an intervention group allowed to strengthen the comparison.

It was also not practical to match participants at all three data collection points: baseline, post-intervention, and follow-up. This was not practical for data protection reasons and also because the staff turnover was too high to allow for meaningful matching. However, we were able to use identifiers to match individuals between post-intervention and follow-up surveys. We also focused the examination on the development of the unit (as opposed to individuals), since the unit was the level of interest and the contextual analysis showed major changes at that level. It is important to match the level of analysis with the focus of change. Since our focus was on the organization rather than on individuals, changes at the collective level over time are most informative when examined using contextual analysis.

In relation to limitations of self-report measures, using a survey for the evaluation may have limited our findings. Although all cautions were followed to protect participants' anonymity and the confidentiality of the data, it is possible that some mistrust or concerns remained about the senior leadership having access to the survey responses. Social desirability [80] and participant self-serving bias [81] may have also influenced the findings, reducing reliability of selfreport surveys. Finally, for practical reasons, it was not possible to use paper surveys at post-intervention and followup, which means that a small percentage of employees may not have been able to participate (although all had access to computers).

Organizational level interventions are as dynamic as organizations themselves. Methodologically, it is important to develop ways to understand the impact of an intervention in the long term and changes of that over time. Reliance on effect evaluation is even more limited in the long term where it is important to document the longevity of change within changeable contexts. Therefore, effect evaluation ought to be supplemented and enhanced by contextual evaluation that can fortify the successful outcomes of an intervention. Akin to action research, evaluation can then become a tool to both monitor and change the course of an intervention, to ensure that it is effective and sustainable. This makes realistic evaluation [8] more pertinent for long-term evaluation, as our study has demonstrated.

\section{Conclusion}

It is not easy to implement a successful organizational intervention and it is equally difficult to document sustainable effects in the long term [58]. In this project the intervention was followed from its launch until five years later to document changes in its effects. Some of the positive effects disappeared when evaluated again at five years. A focus on understanding the context helped us to explain these diminishing effects. Because an intervention is designed to address a specific issue for a specific group and in a specific workplace at a specific time, changes in the context may disrupt potential intervention gains. It is therefore necessary to integrate context awareness and to invest resources in maintaining gains in the long term. This study's offer is the knowledge that consideration an intervention's context can help to understand intervention effects. If context evaluation takes place earlier or, ideally, if it is integrated in the intervention programme, it can help to align intervention efforts and maximize intervention resources to ensure successful and sustainable intervention effects.

\section{References}

[1] Saksvik, P. Ø, Olanyian, S. O., Lysklett, K., Lien, M. \& Bjerke L. (2015). A process evaluation of a salutogenic intervention. Scandinavian Psychologist. 2, e8. http://dx.doi.org/10.15714/scandpsychol.2.e8

[2] Saksvik, P. Ø., Faergestad, M., Fossum, S., Indergård, Ø., Olaniyan, O. S., \& Karanika-Murray, M. (2018) "An effect evaluation of the psychosocial work environment of a university unit after a successfully implemented employeeship program", International Journal of Workplace Health Management, 11 (1), 31-44, https://doi.org/10.1108/IJWHM08-2017-0065

[3] Saksvik, P. Ø., Fossum, S., H., Christensen, M., Lysklett K. \& Karanika-Murray, M. (2020) "Investigating Leadership Qualities to Support Sustainable Intervention Effects in the Long Term". Nordic journal of working life studies, June 2020 .

[4] Christensen, M. Innstrand, S. T., Saksvik, P. Ø. \& Nielsen, K. (2019). The Line Manager's Role in Implementing Successful Organizational Interventions. The Spanish Journal of Psychology, 22, e5, 1-11. doi: 10.1017/sjp.2019.4

[5] Linnan, L. \& Steckler, A. (2002) Process evaluation for public health interventions and research. San Francisco: Jon Wiley and Sons.

[6] Abildgaard, J. S., Saksvik, P. Ø., \& Nielsen, K. (2016). How to measure the intervention process? An assessment of qualitative and quantitative approaches to data collection in the process evaluation of organizational interventions. $\begin{array}{llll}\text { Frontiers in Psychology, } & 7, & 1380 .\end{array}$ https://doi.org/10.3389/fpsyg.2016.01380 
[7] Nielsen, K. (2013). Review Article: How can we make organizational interventions work? Employees and line managers as actively crafting interventions. Human Relations, 66 (8), 1029-1050. https://doi.org/10.1177/0018726713477164

[8] Pawson, R. (2006). Evidence-based policy: a realist perspective. Sage.

[9] Biron, C., Burke, R. J., \& Cooper, C. L. (2014). Creating healthy workplaces: Stress reduction, improved well-being, and organizational effectiveness. Farnham: Gower Publishing Ltd.

[10] Cox, T., Karanika-Murray, M., Griffiths, A., \& Houdmont, J. (2007). Evaluating organizational-level work stress interventions: Beyond traditional methods. Work \& Stress, 21 (4), 348-362. https://doi.org/10.1080/02678370701760757

[11] Dawson, P. (2003). Reshaping change. London: Routledge.

[12] Kristensen, T. (2005). Intervention studies in occupational epidemiology. Occupational and Enviromental Medicine, 62 (3), 205-210. https://doi.org/10.1136/oem.2004.016097

[13] Nytrö, K., Saksvik, P. Ø., Mikkelsen, A., Bohle, P., \& Quinlan, M. (2000). An appraisal of key factors in the implementation of occupational stress interventions. Work \& Stress, 13, 213225 .

[14] Saksvik, P. Ø., Nytrø, K., Dahl-Jørgensen, C., \& Mikkelsen, A. (2002). A process evaluation of individual and organizational occupational stress and health interventions. $\begin{array}{lllll}\text { Work } \quad \& \quad \text { Stress, } 16 & 16 \text { 37-57. }\end{array}$ https://doi.org/10.1080/02678370110118744

[15] Johns, G. (2006). The essential impact of context on organizational behavior. Academy of Management Review, 31, 386-408. https://doi.org/dx.doi.org/10.2307/20159208

[16] Stengers, I. (2011). Thinking with Whitehead: A free and wild creation of concepts. Cambridge, Harvard University Press.

[17] Nielsen, K., \& Abildgaard, J. S. (2013). Organizational interventions: A research-based framework for the evaluation of both process and effects. Work \& Stress, 27 (3), 278-297. doi: $10.1080 / 02678373.2013 .812358$

[18] Latour, B. (2005). Reassembling the social: An introduction to actor-network-theory (Clarendon lectures in management studies). Oxford.

[19] Pawson, R. (2002). Evidece-based policy: the promise of a 'realist synthesis'. Evaluation, 8 (3), 340-358. https://doi.org/10.1177/135638902401462448

[20] Egan, M., Bambra, C., Pettigrew, M., \& Whitehead, M. (2009). Reviewing evidence on complex social interventions: Appraising implementation in systematic reviews of the health effects of organisational-level workplace interventions. Journal of Epidemiology \& Community Health, 63 (1), 4-11. https://doi.org/10.1136/jech.2007.071233

[21] Tsoukas, H., \& Chia, R. (2002). On organizational becoming: Rethinking organizational change. Organization science, 13 (5), 567-582. https://doi.org/10.1287/orsc.13.5.567.7810

[22] Bourbonnais, R., Brisson, C., \& Vézina, M. (2011). Longterm effects of an intervention on psychosocial work factors among healthcare professionals in a hospital setting. Occupational and Environmental Medicine, 68 (7), 479-486. https://doi.org/10.1136/oem.2010.055202

[23] Demerouti, E., Bakker, A. B., Nachreiner, F., \& Schaufeli, W. B. (2001). The job demands-resources model of burnout. Journal of Applied Psychology, 86 (3), 499-512. doi: 10.1037/0021-9010.86.3.499.

[24] Schaufeli, W. B., \& Bakker, A. B. (2004). Job demands, job resources, and their relationship with burnout and engagement: A multi-sample study. Journal of Organizational Behavior, 25 (3), 293-315. doi: 10.1002/job.248.

[25] Ellis A. M., \& Krauss, A. D. (2015). Creating sustained change: Avoiding derailment during the last stage of a wellbeing intervention. In I. C. Biron \& M. Karanika-Murray (Eds.), Derailed organizational interventions for stress and well-being (pp. 221-228). Dordrecht: Springer. DOI 10.1007/978-94-017-9867-9.

[26] Nielsen, K. \& Noblet, A. (2018). Organizational Interventions for Health and Well-being A Handbook for Evidence-Based Practice. London, Routledge.

[27] Innstrand, S. T., Christensen, M., Undebakke, K. G., \& Svarva, K. (2015). The presentation and preliminary validation of KIWEST using a large sample of Norwegian university staff. Scandinavian Journal of Public Health, 43 (8), 855-866. https://doi.org/10.1177/1403494815600562

[28] Tavakol, M., \& Dennick, R. (2011). Making sense of Cronbach's alpha. International Journal of Medical Education, 2, 53-55. https://doi.org/10.5116/ijme.4dfb.8dfd

[29] Tønnessen, E., \& Lie, E. (2018). Gjøvik og Ålesund er mest fornøyd med NTNU-fusjonen. Retrieved from https://khrono.no/ntnu-ntnu-fusjon-fusjon/ny-rapport-gjovikog-alesunder-mest-fornoyd-med-ntnu-fusjonen/226582

[30] Mikkelsen, S. (2018). «Vi må prøve å roe litt ned nå». Universitetsavisa [University Newspaper]. Retrieved from https://www.universitetsavisa.no/campus/2018/04/03/«Vi-måprøve-å-roe-litt-ned-nå»-73250.ece

[31] Vabø, A., Melin, G., Aanstad, S., Borlaug, S. B., \& Dalseng, C. F. (2016). Utviklingen av det nye NTNU. NIFU. Retrieved from https://www.ntnu.no/documents/1262755726/1262827395/NI FU_delrapport 1.pdf/c325a927-e37e-4053-a969a84d14429ab4

[32] Furberg, K. (2017). «Stort arbeidspress på NTNU etter fusjonen». Universitetsavia. Retrieved from https://www.universitetsavisa.no/campus/2017/06/14/Stortarbeidspress-påa-NTNU etter-fusjonen-67136.ece

[33] Oksholen, T. (2018). To av tre ved gamle NTNU mener statusen er svekket. [Two out of three at the old NTNU believe the status is weakened]. Universitetsavisa. Retrieved from

https://www.universitetsavisa.no/campus/2018/06/11/To-avtre-ved-gamle-NTNU-mener-statusen-er-svekket-74805.ece

[34] Cartwright, S., Tytherleigh, M., \& Robertson, S. (2007). Are mergers always stressful? Some evidence from the higher education sector. European Journal of Work and Organizational Psychology, 16 (4), 456-478. https://doi.org/10.1080/13594320701606391

[35] Wan, Y. (2008). Managing Post-Merger Integration: A Case Study of a Merger in Chinese Higher Education. University of Michigan. 
[36] Normannsen, S. (2015). Skal spare 100 mill. midt i fusjon og campussamling. Universitetsavisa. Retrieved from https://www.universitetsavisa.no/politikk/article52349.ece NTNU.

[37] Sverke, M., Hellgren, J., \& Näswall, K. (2006). Job insecurity: A literature review. Arbetslivsinstitutet: Stockholm. Retrieved from http://nile.lub.lu.se/arbarch/saltsa/2006/wlr2006_01.pdf

[38] Lien, M., \& Saksvik, P. Ø. (2016). Healthy change processes: A diary study of five organizational units. Establishing a healthy change feedback loop. Stress \& Health, 32 (4), 258269. https://doi.org/10.1002/smi.2698

[39] Chen, B. \& Krauskopf, J. (2012). Integrated or disconnected? Examining formal and informal networks in a merged nonprofit organization. Nonprofit Management \& Leadership, 23 (3), 325-345. https://doi.org/10.1002/nml.21063

[40] Goedegebuure, L. (2011). Mergers and more: the changing tertiary education architecture in the 21 st century. HEIK Working Papers, 1 (1).

[41] Baumeister, R. F., Bratslavsky, E., Finkenauer, C., \& Vohs, K. D. (2001). Bad is stronger than good. Review of General Psychology, 5 (4), 323-370. https://doi.org/10.1037/10892680.5.4.323

[42] Semmer, N. K. (2006). Job stress interventions and organization of work. Scandinavian Journal of Work, Environment and Health, 32 (6), 515-527. https://doi.org/10.5271/sjweh.1056

[43] Lau, C. M., \& Woodman, R. W. (1995). Understanding organizational change: A schematic perspective. Academy of Management Journal, 38, 537-554. Doi: 10.2307/256692.

[44] Kompier, M., Geurts, S., Gründemann, R., Vink, P., \& Smulders, P. (1998). Cases in stress prevention: the success of a participative and stepwise approach. Stress Medicine, 14 (3), 155-168. https://doi.org/10.1002/(SICI)10991700(199807)14:3<155::AID-SMI773>3.0.CO;2-C

[45] Parkes, K., \& Sparkes, T. (1998). Organizational interventions to reduce work stress: are they effective? A Review of the literature. Sudbury: HSE Books

[46] Sauter, M. \& Murphy, L. (2004). Work organization interventions: state of knowledge and future directions. Sozial$\begin{array}{llll}\text { und } & \text { Präventivmedizin, } 49 & \text { (2), 79-86. }\end{array}$ https://doi.org/10.1007/s00038-004-3085-z

[47] Saksvik, P. Ø., Tvedt, S. D., Nytrø, K., Buvik, M. P., Andersen, G. R., Andersen, T. K., and Torvatn, H. (2007). Developing criteria for healthy organizational change. Work \& Stress. 21, 243-263.

[48] Dahl-Jørgensen, C. \& Saksvik, P. Ø. (2005). The impact of two organizational interventions on the health of service sector workers. International Journal of Health Services, 35 (3), 529-549. https://doi.org/10.2190/P67F-3U5Y-3DDWMGT1

[49] Biron, C., Gatrell, C., \& Cooper, C. L (2010). Autopsy of a failure: evaluating process and contextual issues in an organization-level work stress intervention. International Journal of Stress Management, 17 (2), 13-158. Doi: $10.1037 / \mathrm{a} 0018772$

[50] Lamontagne, A. D., Noblet, A. J. \& Landsbergis, P. A. (2012). Intervention development and implementation: understanding and addressing barriers to organizational-level interventions. In C. Biron, M. Karanika-Murray, \& C. L Cooper (Eds.), Improving Organizational Interventions for Stress and WellBeing: addressing process and context. London: Routledge

[51] Nielsen, K., Randall, R., \& Albertsen, K. (2007). Participants' appraisals of process issues and the effects of stress management interventions. Journal of Organizational Behavior, 28 (6), 793-810. https://doi.org/10.1002/job.450

[52] Nielsen, K., Taris, T. W., \& Cox, T. (2010). The future of organizational interventions: Addressing the challenges of today's organizations. Work \& Stress, 24 (3), 219-233. https://doi.org/10.1080/02678373.2010.519176

[53] Randall, R. \& Nielsen, K. (2012). Does the intervention fit? An explanatory model of intervention success and failure in complex organizational environments. In C. Biron, M. Karanika-Murray, \& C. L Cooper (Eds.), Improving Organizational Interventions for Stress and Well-Being: addressing process and context. London: Routledge.

[54] Landsbergis, P. A., \& Vivona-Vaughan, E. (1995). Evaluation of an occupational stress intervention in a public agency. Journal of Organizational Behavior, 16 (1), 29-48. https://doi.org/10.1002/job.4030160106

[55] Christensen, M., Saksvik, P. Ø., \& Karanika-Murray, M. (Eds.). (2017). The positive side of occupational health psychology. Springer. https://doi.org/10.1007/978-3-319-66781-2

[56] Rottig, D., Reus, T., \& Tarba, S. (2013). The Impact of Culture on Mergers and Acquisitions: A Third of a Century of Research. In C. Cooper \& S. Finkelstein (Eds.), Advances in Mergers and Acquisitions (pp. 135-172). Emerald Books. https://doi.org/10.1108/S1479-361X(2013)0000012009

[57] Vaara, E., Graebner, M., \& Heimeriks, K. (2017). The Process of Postmerger Integration: A Review and Agenda for Future Research. Academy of Management Annals, 11 (1), 1-32. https://doi.org/10.5465/annals.2014.0078

[58] Buono, Anthony R. and Bowditch, James L. (1989). The Human Side of Mergers and Acquisitions - Managing Collisions Between People, Cultures, and Organizations. San Francisco: Jossey-Bass Publishers.

[59] Harman, K. (2002). Merging different campus cultures into coherent educational communities: challenges for higher education leaders. Higher Education, 44 (1), 91-114. https://doi.org/10.1023/A:1015565112209

[60] Sporn, B. (1996). Managing university culture: an analysis of the relationship between institutional culture and management approaches. Higher Education, 32 (1), 41-61. https://doi.org/10.1007/BF00139217

[61] Whetten, D. A. (2006). Albert and Whetten revisited: strengthening the concept of organizational identity. Journal of Management Inguiry, 15 (3), 219-234. https://doi.org/10.1177/1056492606291200

[62] Cartwright, S., \& Schoenberg, R. (2006). Thirty Years of Mergers and Acquisitions Research: Recent Advances and Future Opportunities. British Journal of Management, 17 (S1), S1-S5. https://doi.org/10.1111/j.1467-8551.2006.00475.x

[63] Knippenberg, D., Knippenberg, B., Monden, L., \& Lima, F. (2002). Organizational identification after a merger: A social identity perspective. British Journal of Social Psychology, 41 (2), 233-252. https://doi.org/10.1348/014466602760060228 
[64] Seo, M., \& Hill, N. (2005). Understanding the Human Side of Merger and Acquisition. The Journal of Applied Behavioral Science, $41 \quad$ (4), 422-443 https://doi.org/10.1177/0021886305281902

[65] Tajfel, H., \& Turner, J. (1986). The social identity theory of intergroup behaviour. In S. Worchel \& W. Austin (Eds.), Psychology of intergroup relations (pp. 7-24). Chicago: Nelson Hall.

[66] Turner. (1985). Social categorization and the self-concept: A social cognitive theory of group behaviour. (E. Lawler, Ed.). Greenwich: JAI Press.

[67] Skodvin, O. (1999). Mergers in higher education - success or failure? Tertiary Education and Management, 5 (1), 65-80. https://doi.org/10.1080/13583883.1999.9966981

[68] Giessner, S., Horton, K., \& Humborstad, S. (2016). Identity management during organizational mergers: empirical insights and practical advice. Social Issues and Policy Review, 10 (1), 47-81. https://doi.org/10.1111/sipr.12018

[69] Giæver, F., Vaag, J. R., \& Wennes, G. (2017). Choral singing as an arts-based organisational intervention: A qualitative study of employees' experiences. Arts \& Health, 9 (1), 26-41. https://doi.org/10.1080/17533015.2016.1182564

[70] Milch, V., Vaag, J. R., Giæver, F., \& Saksvik, P. Ø. (2013). Building healthy organizations through music and culture interventions. In G. F. Bauer \& G. J. Jenny (Eds.), Salutogenic organizations and change (pp. 291-305). Dordrecht: Springer. https://doi.org/10.1007/978-94-007-6470-5_16

[71] Zaheer, S., Schomaker, M., \& Genc, M. (2003). Identity versus culture in mergers of equals. European Management Journal, 21 (2), 185-191. https://doi.org/10.1016/S02632373(03)00013-6

[72] Mitleton-Kelly, E. (2005). Co-evolutionary integration-the co-creation of a new organisatational form following a merger or acquisition. Barth, T., Casti, JL, Mitleton-Kelly, E., Sanders, IT, 39-66

[73] Aagaard K., Hansen H. F., Rasmussen J. G. (2016). Mergers in Danish Higher Education: An Overview over the Changing Landscape. In: Pinheiro R., Geschwind L., Aarrevaara T. (eds) Mergers in Higher Education. Higher Education Dynamics. Springer, Cham.
[74] Rafferty, A. E. \& Restubog, S. L. (2009). The impact of change process and context on change reactions and turnover during a merger. Journal of Management, 36 (5), 1309-1338. https://doi.org/10.1177/0149206309341480

[75] Biggs, A., \& Brough, P. (2015). Explaining intervention success and failure: What works, when, and why? In C. Biron \& M. Karanika-Murray (Eds.), Derailed organizational interventions for stress and well-being (pp. 237-244). Dordrecht: Springer. https://doi.org/10.1007/978-94-0179867-9_27

[76] Biron, C., \& Karanika-Murray, M. (2014). Process evaluation for organizational stress and well-being interventions: Implications for theory, method, and practice. International Journal of Stress Management, 21 (1), 85-111. https://doi.org/10.1037/a0033227

[77] Day, A., Crown, S. N., \& Ivany, M. (2017)._Organisational change and employee burnout: The moderating effects of support and job control. Safety science, 100, 4-12.

[78] Camilleri, J., Cope, V., \& Murray, M. (2019). Change fatigue: The frontline nursing experience of large-scale organisational change and the influence of teamwork. Journal of nursing management, 27 (3), 655-660.

[79] Tvedt, S. D., Saksvik, P. Ø., \& Nytrø, K. (2009). Does change process healthiness reduce the negative effects of organizational change on the psychosocial work environment? Work \& Stress, 23 (1), 80-98. doi: $10.1080 / 02678370902857113$.

[80] Donaldson, S. I., \& Grant-Vallone, E. J. (2002). Understanding self-report bias in organizational behavior research. Journal of Business and Psychology, 17 (2), 245260. https://doi.org/10.1023/A:1019637632584

[81] Meltzoff, J. (1998). Critical thinking about research: Psychology and related fields. Washington, D. C.: American Psychological Association.

[82] Biron, C. (2012). WHAT WORKS, FOR WHOM, IN WHICH CONTEXT? RESEARCHING ORGANIZATIONAL INTERVENTIONS ON STRESS AND WELL-BEING USING REALISTIC EVALUATION PRINCIPLES. In: C. Biron, M., Karanika-Murray \& C. Cooper, C. (Eds). Improving organizational interventions for stress and wellbeing: Addressing process and context. London: Routledge. ISBN: 978-1-84872-056-5. 